\title{
Relations between exposure to arsenic, skin lesions, and glucosuria
}

\author{
Mahfuzar Rahman, Martin Tondel, Ireen Akhter Chowdhury, Olav Axelson
}

\begin{abstract}
Objectives-Exposure to arsenic causes keratosis, hyperpigmentation, and hypopigmentation and seemingly also diabetes mellitus, at least in subjects with skin lesions. Here we evaluate the relations of arsenical skin lesions and glucosuria as a proxy for diabetes mellitus.

Methods-Through existing measurements of arsenic in drinking water in Bangladesh, wells with and without arsenic contamination were identified. Based on a questionnaire, 1595 subjects $\geqslant 30$ years of age were interviewed; 1481 had a history of drinking water contaminated with arsenic whereas 114 had not. Time weighted mean arsenic concentrations and mg-years/l of exposure to arsenic were estimated based on the history of consumption of well water and current arsenic concentrations. Urine samples from the study subjects were tested by means of a glucometric strip. People with positive tests were considered to be cases of glucosuria.
\end{abstract}

Results-A total of $430 \quad(29 \%)$ of the exposed people were found to have skin lesions. Corresponding to drinking water with $<0.5,0.5-1.0$, and $>1.0 \mathrm{mg} / 1$ of arsenic, and with the 114 unexposed subjects as the reference, the prevalence ratios for glucosuria, as adjusted for age and sex, were $0.8,1.4$, and 1.4 for those without skin lesions, and 1.1, 2.2, and 2.6 for those with skin lesions. Taking exposure as $<1.0,1.0-5.0,>5.0-10.0$ and $>10.0$ mg-years/ 1 of exposure to arsenic the prevalence ratios, similarly adjusted, were $0.4,0.9,1.2$, and 1.7 for those without and $0.8,1.7,2.1$, and 2.9 for those with skin lesions. All series of risk estimates were significant for trend, $(p<0.01)$.

Conclusions-The results suggest that skin lesions and diabetes mellitus, as here indicated by glucosuria, are largely independent effects of exposure to arsenic although glucosuria had some tendency to be associated with skin lesions. Importantly, however, glucosuria (diabetes mellitus) may occur independently of skin lesions.

(Occup Environ Med 1999;56:277-281)

Keywords: drinking water; glucosuria; keratosis

In Bangladesh, a large part of the population has been drinking water contaminated with arsenic at concentrations $>0.05 \mathrm{mg} / 1,{ }^{1-4}$ the permissible limit by the World Health Organis- ation. Some 30-70 million people are thought to be exposed - that is, the populations of 41 districts out of the 64 in this country. ${ }^{5}$ Exposure to arsenic is known to cause skin disorders such as keratosis, hyperpigmentation, and hypopigmentation. ${ }^{6}$ Recently, epidemiological studies have also indicated an excess risk of diabetes mellitus among subjects exposed to arsenic, either at work or through drinking water. ${ }^{7-10}$ In a previous study from Bangladesh an increased risk of diabetes mellitus was assessed among subjects with skin lesions only, ${ }^{10}$ whereas another study did not consider the question of how the occurrence of diabetes mellitus might relate to skin lesions. ${ }^{7}$ Diabetes mellitus has also been associated with occupational exposure to arsenic in mortality based studies but without any reported association with skin lesions. ${ }^{8}$ Considering a rural population in Bangladesh, we here evaluate the relation of skin lesions and diabetes mellitus taking glucosuria as a proxy for this disease. A clear relation would obviously be of interest for screening purposes in a developing country.

The arsenic contamination of the tubewell water in Bangladesh is probably derived from the fine aluvial sediments of the Ganges delta. ${ }^{4}$ The duration of the exposure to arsenic is uncertain, but it is thought to have started in the late 1960s when drilling of tubewells began as part of a wide irrigation plan. The tubewells have a depth of 20-100 m and the arsenic concentrations may vary widely even between adjacent wells. There has not been any regulation on withdrawal of ground water in Bangladesh and as a result, ground water exploration goes on unchecked, and pumping causes seasonal fluctuations in the water table. These fluctuations could perhaps explain the chemical changes such as oxidation of arsenic containing minerals - such as iron pyritesand subsequent release of arsenic into the groundwater.

Skin lesions - such as hyperpigmentation or hypopigmentation and keratosis - are known as a hallmark of high exposure to arsenic and have been found in populations exposed to well water contaminated with arsenic in Argentina, ${ }^{11}$ Chile, ${ }^{12}{ }^{13}$ India, ${ }^{14-17}$ Taiwan, ${ }^{18} 19$ and Thailand, ${ }^{20}$ but negative findings also have been reported. ${ }^{21}$ Other manifestations resulting from ingestion of drinking water contaminated with arsenic include weakness, conjunctival congestion, oedema, portal hypertension, bronchitis, hepatomegaly, and malignant neoplasm. ${ }^{14}{ }^{15}$

Skin lesions pose a public health problem in Bangladesh. Subjective symptoms are usually mild, but patients with obvious palmoplantar 
keratosis may have pain while walking or working and the disfigurement may lead to social isolation. ${ }^{16} \mathrm{~A}$ question is how closely diabetes mellitus might be associated with the skin lesions and to what extent also subjects without skin lesions can be affected. In our previous study of exposure to arsenic and diabetes mellitus, skin lesions were taken as an indicator of definite exposure. ${ }^{10}$ In the present study, arsenic concentrations ranged from nondetectable to $2.04 \mathrm{mg} / \mathrm{l}$.

\section{Methods}

STUDY AREA

Four villages located in four different districts in Bangladesh (Faridpur, Jessore, Narayongong, and Nawabgong) were selected for the study on the basis of a survey of arsenic in drinking water. These study villages were suitable because of a proper contrast in exposure within the villages. The exact number of wells in each village was not known, but from the existing measurements most of the wells in the study area were known to have arsenic concentrations of $>0.05 \mathrm{mg} / \mathrm{l}$ but a few had no increase in concentrations.

SUBJECTS

All people who had lived in the study areas throughout their lifetime and who had used the same well as long as it had existed, were considered eligible for the study. However, an age restriction was applied because of our previous experience that glucosuria due to exposure to arsenic is unlikely to occur before the age of $30 .{ }^{10}$ Out of 1794 people, a total of 1595 were at home at the time of our visit to the villages and all of them could be interviewed and medically examined, 1481 of whom were exposed.
QUESTIONNAIRE INTERVIEW AND EXAMINATION Data on the duration of water consumption including the water source, a detailed residential history, personal and family history of diabetes mellitus, and hypertension were obtained at an interview with the interviewers filling in a questionnaire.

The interviews and the medical examinations were performed at a door to door visit and carried out by two experienced physicians from the National Institute of Preventative and Social Medicine (NIPSOM), who both had considerable experience in diagnosing arsenical skin lesions in Bangladesh.

Each participant in the study was examined for skin lesions according to the description given by Yeh. ${ }^{22}$ Arsenical skin lesions were diagnosed in the presence of one or more of the following signs: keratosis, hyperpigmentation, or hypopigmentation. Hyperpigmentation occurs anywhere on the body, often as a rain drop-like pigmentation or a diffuse dappling of dark brown, especially marked on the trunk, buttock, and upper thigh. Hypopigmentation follows the same distribution and depigmented spots may be present even in the absence of hyperpigmentation. Keratosis is characterised by diffuse bilateral thickening of palms or soles with or without nodules of various shapes and sizes, most often on the thenar eminence and the lateral borders of palms and fingers.

Standing height and body weight were measured with the subjects having light clothes and not wearing shoes. Individual body mass index (BMI) was calculated as weight $(\mathrm{kg})$ divided by height $(\mathrm{m})$ squared.

EXPOSURE ASSESSMENT

The available data for exposure assessment came from various sources, including our pre-

Table 1 Distribution of exposed subjects with and without skin lesions and cases of glucosuria along with crude prevalence ratios and Mantel-Haenszel prevalence ratios (MH-PR) adjusted by age, sex, and BMI

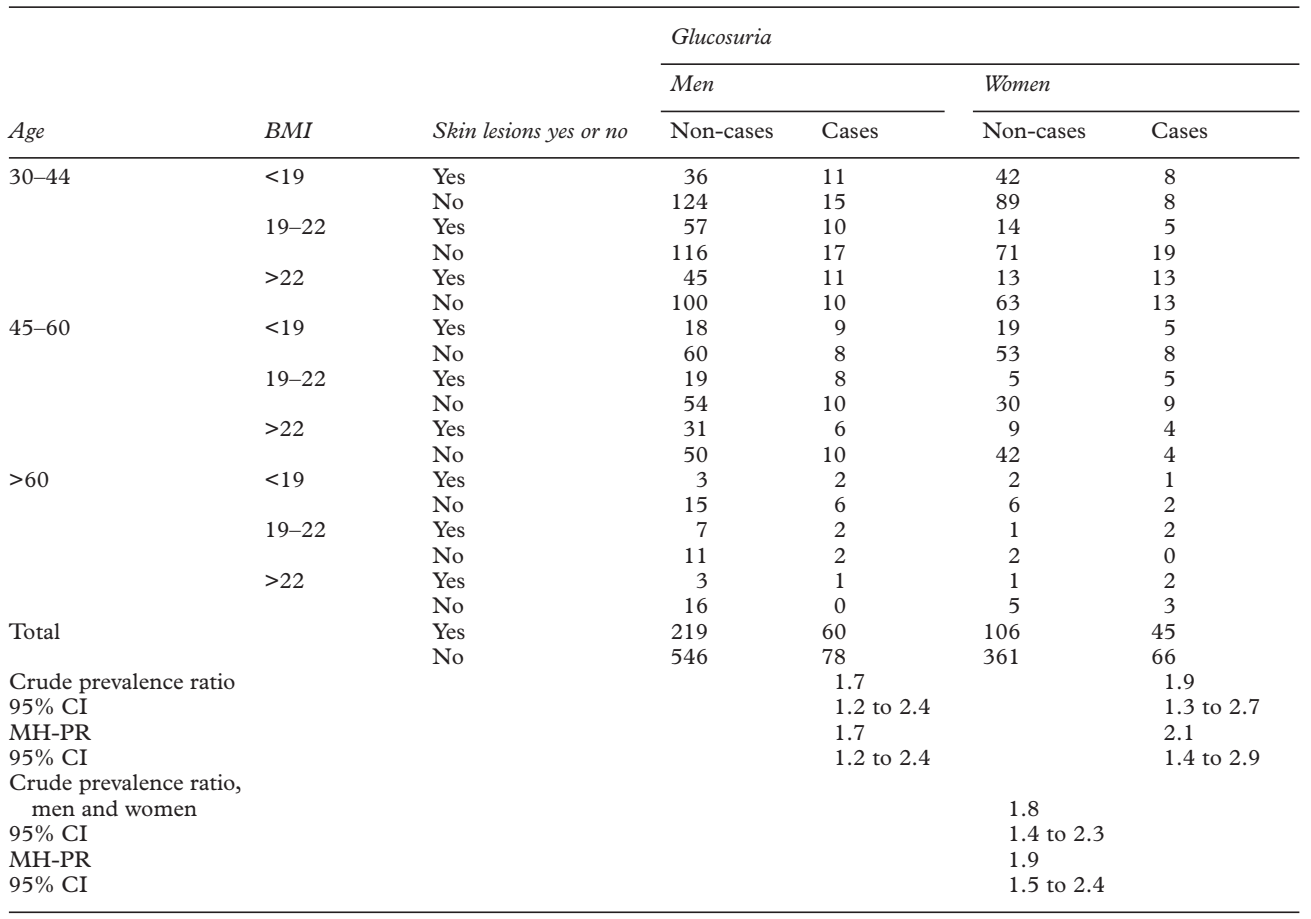


Table 2 Distribution of subjects with and without skin lesions into exposure categories of arsenic concentrations and cases of glucosuria along with Mantel-Haenszel prevalence ratios (MH-PR) adjusted by age and sex and 95\% CI (unexposed is the reference)

\begin{tabular}{|c|c|c|c|c|}
\hline & \multirow[b]{2}{*}{ Unexposed } & \multicolumn{3}{|c|}{ Exposure category ${ }^{\star}$} \\
\hline & & $I$ & $I I$ & $I I I$ \\
\hline \multicolumn{5}{|l|}{ No skin lesions: } \\
\hline Cases & 14 & 47 & 63 & 34 \\
\hline Non-cases & 100 & 434 & 306 & 167 \\
\hline Total & 114 & 481 & 369 & 201 \\
\hline MH-PR & $(1.0)$ & 0.8 & 1.4 & 1.4 \\
\hline $95 \%$ CI & & 0.4 to 1.3 & 0.8 to 2.3 & 0.7 to 2.4 \\
\hline $\begin{array}{l}\chi^{2} \text { For dose-response trend among } \\
\text { the exposed categories }\end{array}$ & & & & $\begin{array}{c}8.9 \\
\mathrm{p}<0.01\end{array}$ \\
\hline \multicolumn{5}{|l|}{ Skin lesions: } \\
\hline Cases & & 19 & 58 & 28 \\
\hline Non-cases & & 123 & 149 & 53 \\
\hline Total & & 142 & 207 & 81 \\
\hline MH-PR & & 1.1 & 2.2 & 2.6 \\
\hline $95 \%$ CI & & 0.5 to 2.0 & 1.3 to 3.8 & 1.5 to 4.6 \\
\hline \multirow{2}{*}{\multicolumn{2}{|c|}{$\begin{array}{l}\chi^{2} \text { For dose-response trend among } \\
\text { the exposed categories }\end{array}$}} & & & 14.4 \\
\hline & & & & $\mathrm{p}<0.001$ \\
\hline
\end{tabular}

${ }^{\star}$ Category I $<0.5 \mathrm{mg} / 1$; category II $0.5-1.0 \mathrm{mg} / 1$; category III $>1.0 \mathrm{mg} / 1$

vious study, ${ }^{10}$ an official report, ${ }^{23}$ and an unpublished report of water analyses performed by the National Institute of Preventive and Social Medicine. As shown elsewhere, ${ }^{2}$ there is considerable variation in arsenic concentrations even between adjacent wells and probably also over time. Details of this are still lacking. The concentrations of total arsenic in drinking water were all measured by flow injection hydride generation atomic absorption spectrometry.

Individual exposure was calculated in two ways. Firstly, we assessed the mean exposure to arsenic for each subject, in principle a time weighted average. Because the subjects had lived all their lives in the same place, the time weighted mean exposure was equal to the measured concentration, assuming that the present concentrations were representative also of the past. The resulting estimates were then categorised as I, II, or III, corresponding to arsenic concentrations of $<0.5 \mathrm{mg} / 1,0.5-1.0$ $\mathrm{mg} / 1$, and $>1.0 \mathrm{mg} / 1$, respectively.

Secondly, mg-years/l of exposure to arsenic were calculated for each subject, multiplying the arsenic concentration in the well by the number of years that it had been used by the person, assuming that the current concentrations of arsenic in the well water were representative of the past. The resulting estimates were then categorised as $<1.0$ mg-years $/ 1,1.0-5.0$ mg-years $/ 1,>5.0-10.0 \mathrm{mg}-$ years/1, and $>10.0 \mathrm{mg}$-years/1.

\section{GLUCOSE STATE}

Urine samples were obtained from all subjects at the time of the health examination. The samples were analysed by means of a glucometric strip (BM-Test Glucose, Boehringer Mannheim GmbH, Mannheim, Germany). People with positive tests were classified as cases.

\section{DATA ANALYSIS}

Subjects were stratified by age (30-44, 45-60, and $>60$ ), sex, and body mass index (BMI); BMI had categories of $<19,19-22$, and $>22$. Mantel-Haenszel weighted prevalence ratios (MH-PRs) with 95\% confidence intervals (95\% CIs) and a test of the trend were calculated by means of the Epi-Info package. ${ }^{24}$

\section{Results}

Out of the 1481 exposed adults who participated in this study (903 men and 578 women), $29 \%(430 / 1481)$ showed at least one of the cutaneous signs of chronic arsenic poisoning. As shown in table 1 , the crude overall prevalence ratio (or risk) for glucosuria in exposed subjects with skin lesions amounted to 1.8. After adjusting for age, sex, and BMI, the prevalence ratio was increased (MH-PR 1.9) Although keratosis was more common in exposed men ( $31 \%$ for men, $26 \%$ for women), the risk for glucosuria was slightly greater in women (MH-PR 1.7 for men $v 2.1$ for women).

As shown in tables 2 and 3, the risk for glucosuria was analysed separately for subjects with and without skin lesions. Considering time weighted mean exposure to arsenic, and taking unexposed people as the reference (table 2), the adjusted prevalence ratios for glucosuria among the subjects without skin lesions were $0.8,1.4$, and 1.4 in exposure categories I, II, and III. With the same reference, subjects with skin lesions had adjusted prevalence ratios of $1.1,2.2$, and 2.6, respectively. The doseresponse was significant (for subjects without skin lesions $\mathrm{p}<0.01$, and with skin lesions $\mathrm{p}<0.001)$. Considering mg-years/l of exposure

Table 3 Distribution of subjects with and without skin lesions into exposure categories of mg-years/l and cases of glucosuria along with Mantel-Haenszel prevalence ratios (MH-PR) (95\% CIs) adjusted by age and sex (unexposed is the reference)

\begin{tabular}{|c|c|c|c|c|c|}
\hline & \multirow[b]{2}{*}{ Unexposed } & \multicolumn{4}{|c|}{ Category of mg-years/l of arsenic exposure } \\
\hline & & $<1.0$ & $1.0-5.0$ & $>5.0-10.0$ & $>10.0$ \\
\hline \multicolumn{6}{|l|}{ No skin lesions: } \\
\hline Cases & 14 & 10 & 61 & 29 & 44 \\
\hline Non-cases & 100 & 159 & 416 & 170 & 162 \\
\hline Total & 114 & 169 & 477 & 199 & 206 \\
\hline MH-PR & $(1.0)$ & 0.4 & 0.9 & 1.2 & 1.7 \\
\hline $95 \%$ CI & & 0.1 to 1.0 & 0.5 to 1.7 & 0.6 to 2.2 & 1.0 to 2.9 \\
\hline $\begin{array}{l}\chi^{2} \text { For dose-response trend among } \\
\text { the exposed categories }\end{array}$ & & & & & $\begin{array}{l}18.11 \\
\mathrm{p}<0.001\end{array}$ \\
\hline \multicolumn{6}{|l|}{ Skin lesions: } \\
\hline Cases & & 7 & 52 & 22 & 24 \\
\hline Non-cases & & 62 & 164 & 58 & 41 \\
\hline Total & & 69 & 216 & 80 & 65 \\
\hline MH-PR & & 0.8 & 1.7 & 2.1 & 2.9 \\
\hline $95 \% \mathrm{CI}$ & & 0.3 to 1.9 & 0.9 to 2.9 & 1.0 to 4.0 & 1.6 to 5.2 \\
\hline $\begin{array}{l}\chi^{2} \text { For dose-response trend among } \\
\text { the exposed categories }\end{array}$ & & & & & $\begin{array}{l}12.16 \\
\mathrm{p}<0.001\end{array}$ \\
\hline
\end{tabular}


to arsenic with the same unexposed people as the reference (table 3), the adjusted risks in subjects without skin lesions showed a clearer dose-response $(0.4,0.9,1.2$, and 1.7). For subjects with skin lesions, the risk estimates were even higher $(0.8,1.7,2.1$, and 2.9, respectively). Both trends were highly significant regardless of skin lesions, $\mathrm{p}<0.001$.

Taking the lowest exposure category as the reference, the risk estimates became higher both for time weighted mean arsenic concentrations and arsenic-years/l, but the overall pattern remained almost the same, with significant trends.

\section{Discussion}

The presence of a stable population in rural villages with different degrees of exposure to arsenic enabled us to study the chronic arsenic poisoning and the relation of skin lesions and glucosuria. There was a dose-response relation between exposure to arsenic and glucosuria for subjects both with and without skin lesions. The mg-years/ 1 of exposure to arsenic may better reflect the total exposure to arsenic than the time weighted average concentrations, for which the dose-response relation also was less clear. The results obtained indicate that skin lesions and glucosuria are largely independent effects of exposure to arsenic although higher risk estimates were obtained for the subjects with skin lesions.

A limitation of the study is the cross sectional design and a lack of systematic sampling of water supplies in the study area. Furthermore, although glucosuria is a primary indicator of diabetes mellitus, it would nevertheless have been desirable to identify the hyperglycaemic patients among those with glucosuria; this was not economically possible, however.

In our study, each person had only one main source of drinking water, with a known arsenic concentration. Arsenic concentrations might vary considerably from well to well in the same area and even in the same well. ${ }^{218}$ The calculated, approximate time weighted exposure to arsenic can obviously not take into account any occasional but unknown use of other wells, nor any time trends in past exposure, or likely fluctuations in the exposure depending on precipitation and other circumstances. Another limitation is the lack of information on the amount of water consumed by each study subject during different periods of his or her lifetime, hampering any more exact calculation of the cumulative exposure to arsenic.

It is not known whether other trace elements could be of importance as present in water together with arsenic. However, there is no definite evidence of the presence of other toxic trace elements in the study area, nor is it clear whether any other elements would have an influence on the occurrence of glucosuria.

This study also has some other limitations to be discussed. Not all primarily identified subjects were finally available at the time of the door to door visit. As all study subjects were recruited from rural villages, occupation, socioeconomic status, and lifestyle variables should be reasonably similar between exposed and unexposed people and should therefore be unlikely to influence glucosuria either in the presence or absence of skin lesions. There was an indication of some slight negative confounding for women for age and BMI, for which adjustments were made (table 1). Also when applying a linear regression model, BMI exerted weak negative confounding and was therefore not taken into account in further analyses.

Inorganic arsenic is known to induce blackfoot disease and seemingly also ischaemic heart disease through a direct effect on the atherosclerotic process involving endothelial cells, smooth muscle cells, platelets, and macrophages. ${ }^{25}$ Diabetes mellitus is another important determinant for peripheral vascular disease and ischaemic heart disease. Thus, cardiovascular diseases might also be caused indirectly through arsenic induced diabetes mellitus. A transient hyperglycaemia and structural $\beta$-cell changes were found in mice treated with arsenite plus hydroxylamine. ${ }^{26}$ Besides a potentially toxic effect on the $\beta$-cells, arsenic might act on the peripheral insulin receptor in the tissue, causing diabetes mellitus. There is also an indication that trivalent arsenic may induce hyperglycaemia acting on the central nervous system. ${ }^{27}$ Arsenic has been reported to induce renal insufficiency after cortical necrosis with haematuria, leukocyturia, and glucosuria. ${ }^{28}$ Whether the glucosuria is caused by any or several of these mechanisms needs further exploration. There is also a need for further evaluating how well glucosuria serves as a proxy for diabetes mellitus in subjects exposed to arsenic.

This is the first population based study considering the relation of skin lesions and risk for glucosuria and thereby also diabetes mellitus. On the basis of our findings, we conclude that the appearance of dermatological signs of chronic arsenic toxicity is a poor marker for a risk of glucosuria and diabetes mellitus, as these conditions may well occur also in the absence of skin lesions.

We thank Drs Sk Akhtar Ahmad and MH Faruquee, Department of Occupational and Environmental Health, NIPSOM, Dhaka, Bangladesh, for their support, especially in the field survey, and for providing existing water measurements by NIPSOM. The study was approved by the ethics committee of Bangladesh Medical Research Council, and participation was voluntary.

1 Dhar RK, Biswas BK, Samanta G, et al. Groundwater arsenic calamity in Bangladesh. Current Science 1997;73:48-59.

2 Biswas BK, Dhar RK, Samanta G, et al. Detailed study report of Samta, one of the arsenic-affected villages of Jessore district, Bangladesh. Current Science 1998;74:134-45.

3 Khan AW, Ahmad SA, Sayed SU, et al. Arsenic contamination in ground water and its effect on human health with particular reference to Bangladesh. F Prev Soc Med 1997; 16:65-73

4 Bagla P, Kaiser J. India's spreading health crisis draws global arsenic experts. Science 1996;274:174-5.

5 Dhaka Community Hospital. International conference on arsenic pollution of ground water in Bangladesh: causes, effects, and remedies. Dhaka: Dhaka Community Hospital, 1998.

6 World Health Organization. Environmental health criteria 18: arsenic. Geneva: World Health Organization, 1981.

7 Lai MS, Hsueh YM, Chen CJ, et al. Ingested inorganic arsenic and prevalence of diabetes mellitus. Am f Epidemiol 1994;139:484-92.

8 Rahman M, Wingren G, Axelson O. Diabetes mellitus among Swedish art glassworkers-an effect of arsenic exposure? Scand f Work Environ Health 1996;22:146-9. 
9 Rahman M, Axelson O. Diabetes mellitus and arsenic exposure: a second look at case-control data from a Swed-
ish copper smelter. Occup Environ Med 1995;52:773-4.

10 Rahman M, Tondel M, Ahmad SA, et al. Diabetes mellitus associated with arsenic exposure in Bangladesh. Am F Epidemiol 1998;148:189-203.

11 Biagini RE. Consideraciones actuales sobre hidroarsenicismo cronico regional endemico (HACRE). La Semana Medica 1974;145:2171-9.

12 Zaldivar R. Arsenic contamination of drinking water and foodstuffs causing endemic chronic poisoning. Beiträge zur Pathologie 1974;151:384-400.

13 Borgono JM, Vicent P, Venturino $\mathrm{H}$, et al. Arsenic in the drinking water of the city of Antofagasta: epidemiological and clinical study before and after the installation of a treatment plant Environ Health Perspect 1977;19:103-5.

14 Guha Mazumder DN, Chakraborty AK, Ghose A, et al. Chronic arsenic toxicity from drinking tubewell water in Chronic arsenic toxicity from drinking tubewell water in
rural West Bengal. Bull World Health Organ 1988;66:499506.

15 Guha Mazumder DN, Das Gupta J, Santra A, et al. Non-cancer effects of chronic arsenicosis with special reference to liver damage. In: Abernathy CO, Calderon RL, Chappell WR, eds. Arsenic exposure and health effects. London: Chapman and Hall, 1997:112-23.

16 Das D, Chatterjee A, Samanta G, et al. Arsenic contamination in groundwater in six districts of West Bengal, India: the biggest arsenic calamity in the world. Analyst 1994;119: $168 \mathrm{~N}-70 \mathrm{~N}$. 17 Guha Mazumder DN, Gupta JD, Chakraborty AK, et al.
Environmental pollution and chronic arsenicosis in South Calcutta. Bull World Health Organ 1992;70:481-5.
18 Tseng WP, Chu HM, How SW, et al. Prevalence of skin cancer in an endemic area of chronic arsenicism in Taiwan. $\mathcal{F}$ Natl Cancer Inst 1968;40:453-63.

19 Tseng WP. Effects and dose-response relationships of skin cancer and blackfoot disease with arsenic. Environ Health Perspect 1977;19:109-19.

20 Foy HM, Tarmapai S, Eamchan P, et al. Chronic arsenic poisoning from well water in a mining area in Thailand. Asia Pac F Public Health 1992;6:150-2.

21 Harrington JM, Middaugh JP, Morse DL, et al. A survey of a population exposed to high concentrations of arsenic in well water in Fairbanks, Alaska. Am f Epidemiol 1978;108: 377-85.

22 Yeh S. Skin cancer in chronic arsenicism. Hum Pathol 1973; 4:469-85.

23 Khan AW, Ahmad SA. Arsenic in drinking water. Health effects and management. A training manual. Dhaka: Department of Occupational and Environmental Health. National InstiOccupational and Environmental Health. National Insti-
tute of Preventive and Social Medicine (NIPSOM), 1997.

tute of Preventive and Social Medicine (NIPSOM), 1997. Cean JA, Dean AG, Burton A, et
Centers for Disease Control, 1988 .

25 Ross R. The pathogenesis of atherosclerosis: an update. $N$ Engl f Med 1986;314:488-500.
Ens

26 Boquist L, Boquist S, Ericsson I. Structural $\beta$-cell changes and transient hyperglycemia in mice treated with compounds inducing inhibited citric acid cycle enzyme activity. Diabetes 1988;37:89-98

27 Kawaguchi I. Studies on $\mathrm{As}_{2} \mathrm{O}_{3}$-induced hyperglycemia. Nippon Yakurigaku Zasshi 1981;78:213-22. (In Japanese.)

28 Gerhardt RE, Hudson JB, Rao RN, et al. Chronic rena insufficiency from cortical necrosis induced by arsenic poisoning. Arch Intern Med 1978;138:1267-9. 